\title{
AS TÉCNICAS DA ENGENHARIA NATURAL COMO ALTERNATIVA A ENGENHARIA CONVENCIONAL - ESTUDO DE CASO EM OBRAS DE CONTENÇÃO DAS MARGEM DO RIO ITAJAÍ-AÇU EM BLUMENAU-SC.
}

DOI: 10.37702/2175-957X.COBENGE.2021.3696

Rodrigo Boeing Althof - eng.rodrigoalthoff@gmail.com

Instituto Federal Catarinense IFC

Rua Hercílio Fides Zimmermann 15

89116-650 - Gaspar - SC

Resumo: A dinâmica natural dos cursos de água tem sofrido constantes ações de origem antropogênicas, que alteram a estabilidade das encostas e taludes dos rios. Estes impactos podem ser mitigados ou evitados por meio de obras adequadas da engenharia civil ou por meio da bioengenharia. Normalmente as técnicas da bioengenharia são utilizadas em conjunto com os princípios ecológicos, usando a vegetação e materiais inertes para estabilizar e conter encostas. Diante deste contexto o objetivo deste trabalho foi analisar algumas das obras executadas pela engenharia convencional, nas margens do rio Itajaí-Açu próxima à ponte Adolfo Konder em Blumenau-SC. E avaliar como a bioengenharia pode contribuir para oferecer maior eficiência às obras, reduzindo os custos, aumentando a vida útil e consequentemente, acarretando menores impactos ambientais associados. Ao mesmo tempo se observou que a cobertura vegetal presente nas margens tem sido significativamente eficiente no controle de erosões e escorregamento de solo.

Palavras-chave: Engenharia natural. Bioengenharia. Sustentabilidade. 


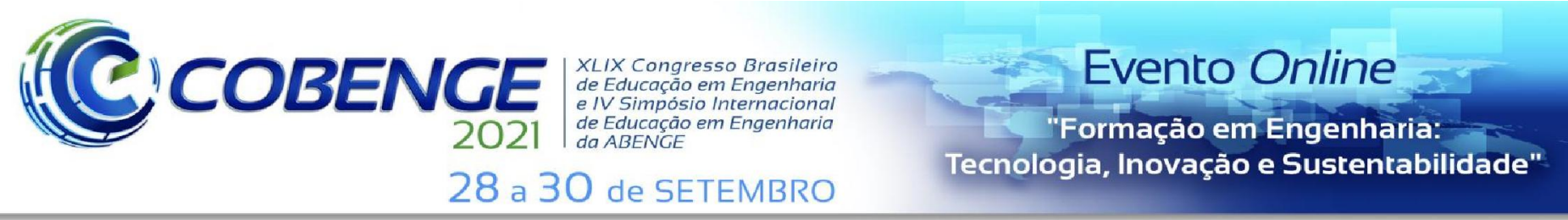

\section{AS TÉCNICAS DA ENGENHARIA NATURAL COMO ALTERNATIVA A ENGENHARIA CONVENCIONAL - ESTUDO DE CASO EM OBRAS DE CONTENÇÃO DAS MARGEM DO RIO ITAJAÍ-AÇU EM BLUMENAU-SC}

\section{INTRODUÇÃO}

Em um contexto de mudanças climáticas globais, as cidades tendem a ser atingidas por fenômenos climáticos extremos com maior frequência e intensidade. Tendo em vista a tendência global da concentração da população nas cidades, o planejamento urbano precisa incorporar o conhecimento das vulnerabilidades e dos riscos ao qual a população está sujeita. Podendo assim, propor medidas de mitigação e adaptação que aumentem a resiliência urbana (IPCC, 2014).

Este fato possibilita a capacidade da sociedade absorver perturbações e manter o seu funcionamento. Caso isso não ocorra, as cidades se transformarão em armadilhas com imenso potencial a desastres naturais.

A dinâmica natural dos cursos de água tem sofrido constantes ações antropogênicas, que alteram a estabilidade das encostas dos rios (POMPÊO, RIGOTTI e FREITAS FILHO, 2011). Até mesmo as ações oriundas dos processos naturais vêm sendo degradadas. As matas presentes nas encostas e nas margens dos rios vêm sofrendo grandes transformações na sua paisagem natural promovidas pela ação do homem (PEREIRA, 2008).

Diante disso, há necessidade de proteger os recursos naturais e encontrar um equilíbrio entre as atividades humanas e o sistema ecológico. Mas muitas vezes o pensamento de melhorar as intervenções humanas nas mudanças do meio ambiente preconiza a inserção excessiva de sistemas artificiais em construções que contrariam o processo natural (SCHMEIER, 2012). Os sistemas atrelados à engenharia civil e na grande maioria preconizados por ações de engenharia "política" são constantemente usados na tentativa de dominar a natureza.

A quantidade de água em contato com o solo é um dos fatores determinantes no processo de erosão e da vida útil das obras de engenharia. A implantação ou a estabilização da vegetação nas margens dos rios é fundamental para a contenção de encostas e taludes nas margens de rios (SILVA 2008). Isso pode ser observado nas áreas de mata ciliares menos impactadas pelas ações do homem. A vegetação ciliar promove uma maior estabilização dos taludes, impede a aceleração da dinâmica erosão/sedimentação e consequentemente assoreamento dos rios (HOLANDA et al., 2010). Além da contenção da erosão nas áreas vegetadas nas margens de rios e córregos contribuem para a manutenção da biodiversidade e o equilíbrio dos ecossistemas (MELO et al., 2013).

As áreas de matas ciliares nas margens do rio Itajaí-Açu vêm apresentando grandes transformações em sua paisagem original, promovidas pelas ações do homem em resposta ao crescimento populacional da cidade. Isso tem gerado principalmente reflexo direto no segmento ambiental, e em um amplo espectro socioeconômico.

A erodibilidade das margens dos rios é uma das manifestações mais visíveis do complexo reajustamento da morfologia do canal do rio em busca de um novo equilíbrio dinâmico e das alterações na dinâmica do sistema fluvial. Isso promove um contínuo trabalho de escavação na base da margem côncava, onde a velocidade é maior, e de deposição na parte convexa onde a velocidade diminui (GUERRA e CUNHA, 2003). De acordo com Bandeira (2005), os rios estão sempre em busca de um equilíbrio, erodindo seus leitos e transportando o sedimento de um lado para outro. 


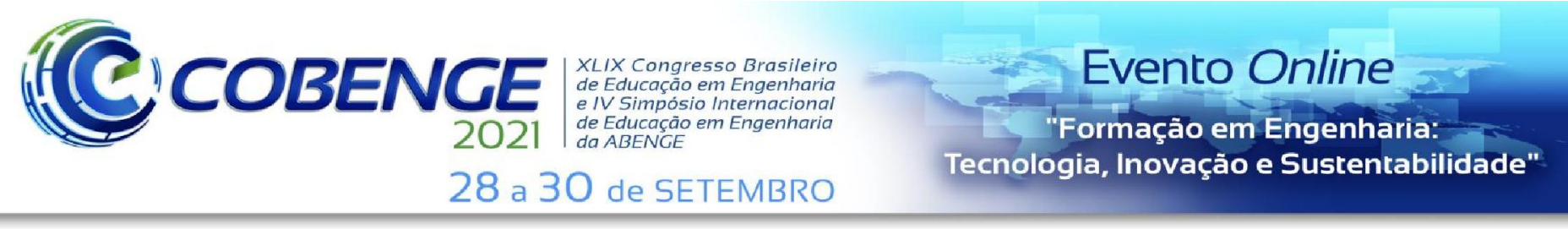

Os processos erosivos acontecem quando a todas as forças atuantes sobre o material erodido ultrapassa o resultado efetivo de todas as forças que tendem a manter o material no próprio local (SIMONS, 1982). Os impactos podem ser mitigados ou evitados por meio de obras adequadas da engenharia civil ou da bioengenharia (BRANDÃO, 2001; HOLANDA et al., 2005; HOLANDA et al. 2007).

Dentro deste contexto foi realizada uma visita técnica as margens do rio Itajaí-Açu, próximo à ponte Adolfo Konder localizada no município de Blumenau-SC. O objetivo foi comparar as obras executadas pela engenharia convencional no controle no controle dos processos erosivos e na estabilização das margens com e as áreas que ainda permanecem vegetadas.

\section{ENGENHARIA CONVENCIONAL E ENGENHARIA NATURAL}

A engenharia convencional apresenta diversas técnicas para estabilização e contenção de encostas, como por exemplo, muros de concreto ciclópico, armado, gabiões, contenção de solo cimento ensacado, muros de pedra seca, argamassada, cortinas atarantadas, solo reforçado com manta geotêxtil, dentre outros. Os métodos tradicionais costumam focar em soluções específicas diretamente no problema, sem levar em conta as consequências que poderão advir da intervenção realizada. A função do equilíbrio, normalmente, é interrompida quando os métodos tradicionais são usados para forçar condições artificiais (LI e EDDLEMAN, 2002).

As técnicas de engenharia natural ou bioengenharia de solos são realizadas há séculos para conter erosão de margens de rios em diferentes partes do mundo (FATAHI et al., 2010). Segundo Fatahi a engenharia natural compreende um conjunto de técnicas e práticas que utilizam plantas vivas, preferencialmente autóctones, como elemento do processo construtivo, juntamente ou não com outros materiais (pedra, madeira, metal), no domínio da restauração ambiental.

As técnicas da bioengenharia são utilizadas em conjuntos com os princípios ecológicos, usando a vegetação e outros materiais inertes para estabilização de encostas e taludes (GOLFARI e CASER, 1977; GRAY e SOTIR, 1996).

O uso da bioengenharia pode ser aplicado por si só ou atreladas às técnicas convencionais de engenharia civil. Segundo Sutili et al., (2004) e Araújo-Filho et al., (2013) a combinação de técnicas da bioengenharia de solos com técnicas da engenharia convencional promove o desenvolvimento da vegetação, proporcionando a proteção e estabilização dos taludes das margens de rios. Ainda segundo esses autores as técnicas de bioengenharia são rentáveis, pois podem ser aplicadas em áreas remotas, utilizando materiais disponíveis no local, exigência de trabalho de baixo custo em comparação com as obras elaboradas pela engenharia convencional e compatibilidade ambiental (COUTO et al., 2010).

A bioengenharia é considerada multidisciplinar, por combinar diversas áreas como a engenharia a pedologia, geotécnica, hidráulica, hidrogeologia e do meio abiótico (DIAS, 2011). O objetivo do método é aproveitamento as propriedades naturais da vegetação de forma a estabilizar o solo. Um dos atributos da vegetação é a melhoria nas condições hidráulicas do solo, promovendo maior infiltração e disponibilidade de água, reduzindo assim o processo de erosão (ARAÚJO et al., 2013).

Normalmente as técnicas da engenharia natural não necessitam da utilização de equipamentos ou de movimentação de solo, o que propicia uma menor perturbação durante a concretização de obras de proteção de taludes e controle de erosão. Os locais em que o acesso é difícil ou até mesmo inacessível para o uso de máquinas, as técnicas da 


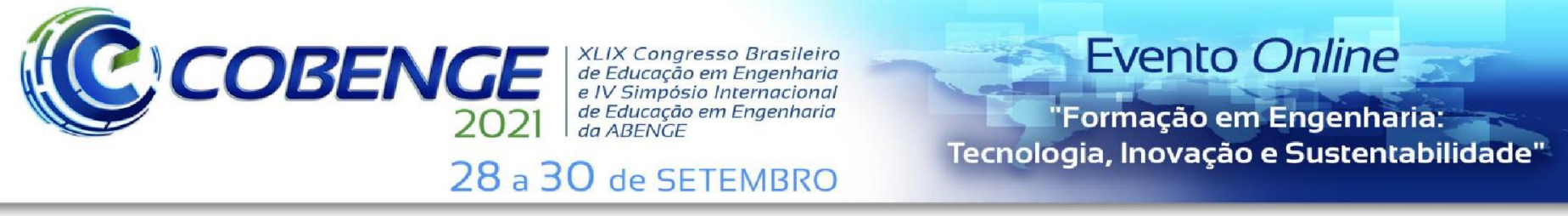

engenharia natural podem ser a uma das únicas alternativas viáveis para a execução da obra. Isso foi confirmado por ZEH (2007) que comparou as técnicas da engenharia natural com as clássicas da engenharia convencional, e a grande vantagem está no aspecto econômico, no qual diz respeito aos custos de obras e aos custos de manutenção e reparação. De acordo com Allen (1997), dentro do aspecto econômico a bioengenharia é muito mais econômica em longo prazo, por ser resiliente e autossustentável.

A vegetação assegura a estabilização e a proteção do solo através do seu sistema radicular, desenvolve um modo de equilíbrio. Trata-se de uma estratégia biológica e ecológica que permite uma valorização estética e paisagística da construção. Algumas das desvantagens apontadas a esta técnica é a de não satisfazer os requisitos de segurança exigidos e apenas atingir eficiência após um determinado intervalo de tempo. Além disso, ocorre perda de eficiência devido à sua degradação e a falta de capacidade de regeneração, que não cumprem qualquer função biológica e normalmente constituem elementos estranhos na paisagem. As grandes vantagens estão ligadas a maior estabilidade, independência das características do local e da aplicação menos limitada temporalmente e a funcionalidade em curto prazo. Mas muitas vezes, são usados sistemas combinados, aproveitando assim, as vantagens de ambos os materiais (SILVA 2010).

A vegetação afeta a estabilidade dos solos por intermédio das raízes, devido ao aumento da resistência da coesão, maior infiltração e resistência do solo (BURYLO et al., 2009). A camada radicular da vegetação tem um papel importante no processo de estabilização das encostas e taludes dos rios (ARAÚJO et al., 2005). As raízes de menores dimensões, com menor diâmetro têm uma capacidade de captar água nos vazios dos solos, conferindo-lhes maior agregação, enquanto as de maiores dimensões conferem uma maior estabilidade (COELHO e PEREIRA 2006).

Existe uma necessidade de compreender as caraterísticas locais, com o objetivo de escolher mais acertadamente as espécies vegetais a ser implantadas, visando à obtenção de uma estabilização mais efetiva, visto que as raízes e a sua arquitetura são governadas tanto pela genética como pelas caraterísticas locais. A seleção da vegetação a ser aplicada na recuperação de uma encosta ou obra de engenharia, deve-se ter o cuidado na sua escolha. Para Pereira (2008) é de suma importância o conhecimento das espécies que serão implantadas nas áreas de contenção. Segundo Li et al., (2012) a seleção da espécie de planta é muito importante, pois ela deve ter caráter pioneiro e propagação rápida e simples. A vegetação natural da região ou vegetação autóctone, geralmente possui uma melhor adaptação às condições naturais de sua origem (ANGELIS NETO et al., 2004). Dentre as vantagens, a vegetação nativa é altamente resistente às mudanças do ambiente e das variações climáticas (PETERSEN 2004). Esta escolha baseia-se em diversos critérios, como as características biotécnicas das plantas e do local da obra. A vegetação deve ser o mais heterogêneo possível, evitando assim a formação de comunidades de apenas uma espécie, que contribuem muito pouco para a dinâmica da vegetação.

\section{3 ÁREA DE ESTUDO}

O estudo consistiu na análise de algumas das obras executadas nos últimos anos pela engenharia convencional nas margens do rio Itajaí-Açu, em uma área localizada próxima a ponte Adolfo Konder (Figura 1). Também foi realizada uma avaliação de como a bioengenharia de solos pode ser usada como um instrumento para aumentar à eficiência as obras, reduzindo os custos, aumentando a vida útil e consequentemente, acarretando menores impactos ambientais associados aos deslizamentos de encostas e taludes. 
A bacia hidrográfica do Itajaí-Açu está localizada entre as coordenadas geográficas $48^{\circ} 38^{\prime}$ e $50^{\circ} 21^{\prime}$ W e $26^{\circ} 22^{\prime}$ e $27^{\circ} 53^{\prime}$, na região leste de Santa Catarina. Medindo aproximadamente $15.500 \mathrm{~km}^{2}$, limitando-se do litoral até o planalto catarinense, equivale a $16,5 \%$ do território estadual e a $0,6 \%$ do território nacional. Dentro da bacia do Itajaí encontram-se 53 municípios, dos quais 47 têm sua sede dentro da bacia, onde habitam cerca de 1 milhão de habitantes. Constituído dentro da região hidrográfica do Vale do Itajaí - RH7- compõe o principal curso de água dentro da rede hidrográfica do estado de Santa Catarina, e é a maior bacia hidrográfica da Vertente Atlântica (SAMAE, 2002; VIBRANS et al., 2003).

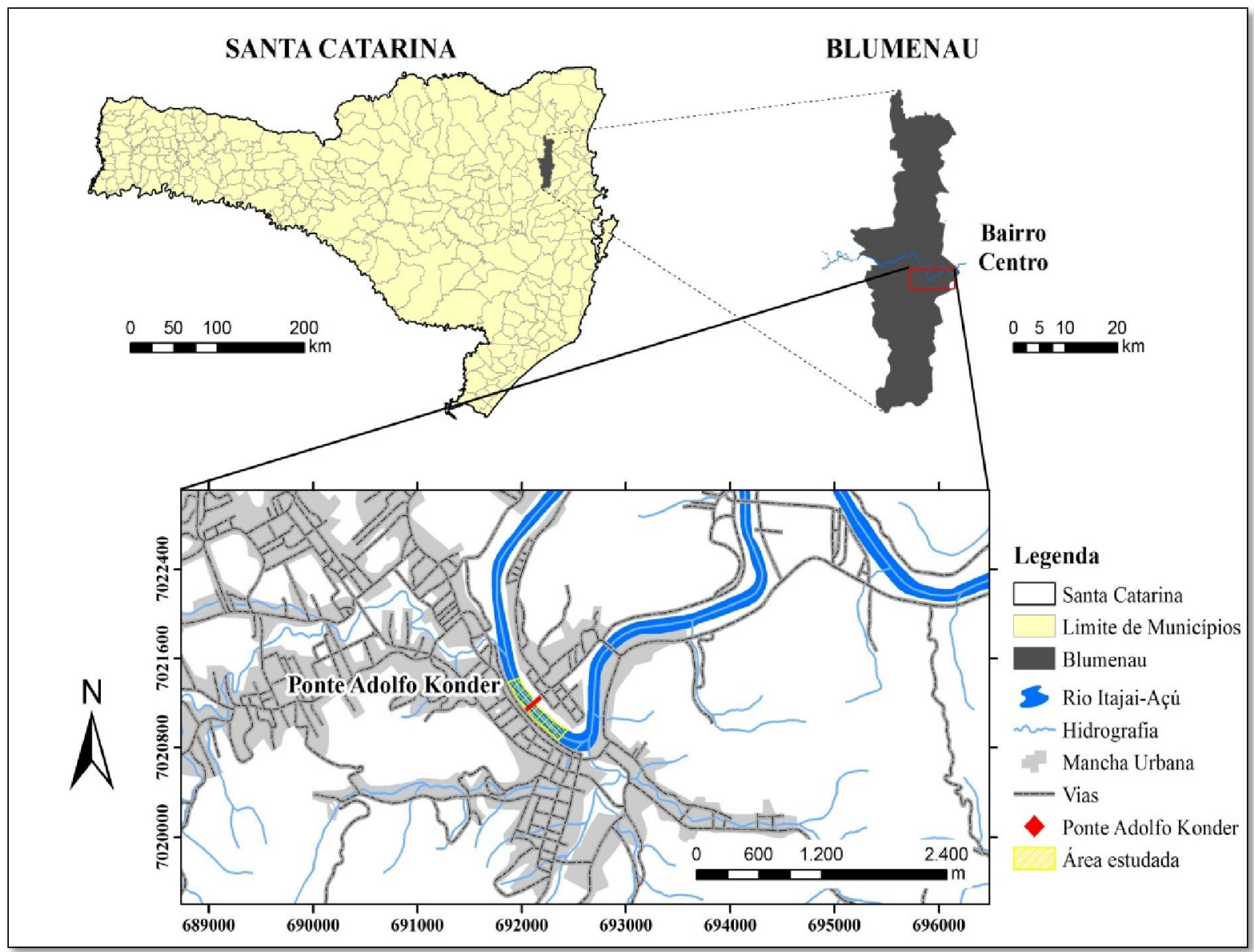

Figura 1. Localização da área de estudo.

A região possui regime tropical com seus afluentes e formadores caracterizados por trechos com declives acentuados. A distribuição pluviométrica é bastante regular e uniforme ao longo do ano, alcançando valores em torno de $2.000 \mathrm{~mm}$ (SEVERO 2009). Sua densidade de drenagem de $1,61 \mathrm{~km} . \mathrm{km} 2 \mathrm{com}$ uma vazão média de longo período de $205 \mathrm{~m}^{3} . \mathrm{s}-1$, caracteriza a bacia do rio Itajaí como uma das mais significativas e importantes do estado, tanto em aspectos hidrográficos como socioeconômicos. Ressaltando que todos os cursos d'água da região aos quais potencialmente podem receber o lançamento de efluentes tratados ou não, está inserida na bacia hidrográfica do rio Itajaí-Açu, atuando assim como um corpo receptor final de todos os efluentes gerados e lançados dentro na bacia (SAMAE, 2002). 
No ano de 2000, Vibrans demonstrou o uso e ocupação da cobertura florestal da bacia do Itajaí a partir de dados de sensoriamento remoto evidenciando que $22 \%$ da área da bacia estão cobertos por áreas lavouras e pastagens, 1,2\% por plantações de arroz, $2,6 \%$ por áreas urbanizadas, $54 \%$ são cobertos por florestas secundárias e primárias, $12 \%$ por capoeiras, $1 \%$ por capoeirinhas e $2 \%$ por reflorestamentos.

O principal rio da bacia é o rio Itajaí-Açu, e possui um comprimento de 191 quilômetros com uma declividade média variando de 4,4 a $6,5 \mathrm{~m} / \mathrm{km}$ (SANTA CATARINA, 1997).

As avaliações consistiram em visitas as duas margens do rio Itajaí-Açu, observando as obras realizadas a partir de 2014 e como se encontram no momento. Análise das obras que estão sendo realizadas, que tipo de obra e a forma como estão sendo implantadas. E a análise das áreas que a vegetação ainda se mantem intacta. Diante disso foram feitas as avaliações separadas e a o cruzamento entre tais.

\section{RESULTADOS E DISCUSSÃO}

Foi verificado que na margem direita do rio Itajaí-Açu, próximo à ponte Adolfo Konder, que as obras de contenção realizadas pela engenharia convencional estão se deteriorando (figura 2b). Neste ponto pode-se visualizar pedras soltas oriundas de contenções passadas.

De acordo com esta imagem podemos designar que neste local já foi realizado a contenção da margem pelo método de enrocamento. Também percebemos que o enrocamento foi realizado por si só, ou seja, nenhuma outra técnica conjunta foi utilizada. Segundo Holanda et al., (2001), o enrocamento de margens de rios deve ser utilizado somente em caráter emergencial.

Diante disso, concluímos que se projeto tivesse abordado o uso de uma segunda técnica como a da bioengenharia, esta obra poderia ter seu prazo de validado prolongado.

Figura 2. Ação da vegetação na contenção de sedimentos (a); ineficiência do processo de contenção de



Fonte: Autor

Na figura 2a está evidenciado o potencial de retenção de sedimento pela vegetação, com o acúmulo de sedimento a montante da área vegetada.

Segundo Liu et al., (2014) e Li et al., (2015) a vegetação age eficientemente contra agentes erosivos como as gotas de chuva, aumento da infiltração da água no solo e a 


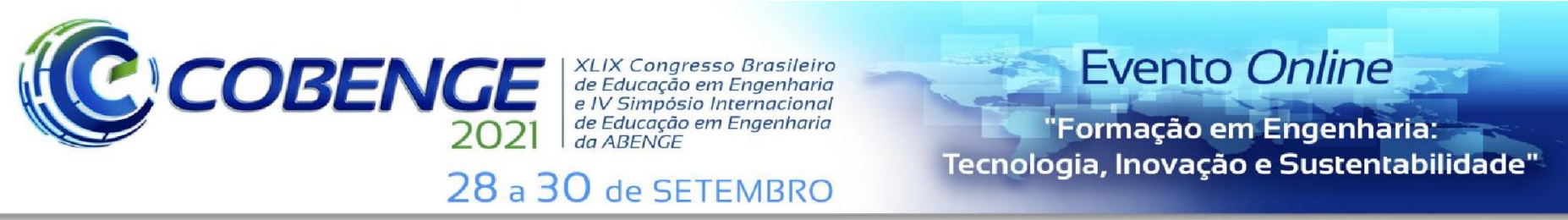

protegidas com cobertura vegetal, o controle da erosão tem sido significativamente eficiente.

Dentro das técnicas da engenharia civil, o processo de enrocamento tem sido o de maior utilização, uma vez que sua aplicação é mais fácil e de menor custo quando comparadas a muros e cortinas atirantadas. Em uma análise temporal percebe se que em algumas áreas o processo de fluxo e refluxo tem retirado o material granular fino, comprometendo a durabilidade da estrutura e exigindo constantes manutenções.

\section{CONCLUSÃO}

A engenharia natural, seja através da bioengenharia ou de outras ações, não visa concorrer com as técnicas tradicionais da engenharia convencional para a estabilização de encostas, apesar de que em algumas situações se mostra como uma alternativa mais econômica frente às obras tradicionais de engenharia.

A água é principal agente, mas diversos fatores influenciam nos movimentos gravitacionais, como o relevo, as características geológicas e geotécnicas do solo, a ausência de vegetação, as características climáticas da região, o nível freático e principalmente as intervenções humanas.

A bioengenharia de solos se apresenta como uma das formas mais eficazes na contenção da erosão, pois pode promover o reforço do talude sem necessidade de cálculos estruturais complexos, além de possibilitar o emprego de matéria prima disponível na região, reduzindo-se os custos e os impactos ambientais diretos e indiretos das obras convencionais.

Respeitar a legislação ambiental, não ocupando as áreas de preservação permanente, desocupar as áreas de risco, adaptar os projetos de engenharia ao meio físico que ele esteja inserido, maior fiscalização por parte dos órgãos gestores e principalmente maior educação ambiental, podem reduzir significativamente os deslizamentos nas encostas de rios.

\section{REFERÊNCIAS}

ANGELIS NETO, G.; ANGELIS, B. L. D.; OLIVEIRA, Daniel S. de. O uso da vegetação na recuperação de áreas urbanas degradadas. Acta Scientiarum. Technology, v. 26, p. 6573, 2004.

ARAÚJO - FILHO, R. N.; HOLANDA, F. S. R.; ANDRADE, K. R. Implantação de técnicas de bioengenharia de solos no controle da erosão no baixo São Francisco. Scientia Plena, v. 7, n. 1, 2013.

ARAÚJO, G.; ALMEIDA, J.; GUERRA, A. Gestão ambiental de áreas degradadas. Rio de Janeiro: Bertrand Brasil, 2005. 320 p.

BANDEIRA, A. A. Evolução do processo erosivo na margem direita do rio São Francisco e eficiência dos enrocamentos no controle da erosão do trecho em estudo. 2005 f. Dissertação (Mestrado em Desenvolvimento e Meio Ambiente (PRODEMA)), Universidade Federal de Sergipe, São Cristóvão, 2005. 




BRANDÃO, J. L. B. Obras de regularização do leito. Tese (Doutorado em Engenharia Civil) - Escola Politécnica da Universidade de São Paulo, São Paulo, 2001.

BROOKES, A. Channelized rivers: Perpectives for enviromental Management. WileyIntercience, p. 326, 1988.

BURYLO, A.; REY, F.; ROUMET, C.; BUISSON, E.; DUTOIT, T. Linking plant morphological traits to uprooting resistense in e roded Marly lands (Southern Alps, France). Plnat and Saoil, v. 324, n. 324, p. 31-42, 2009.

COELHO, A. T.; PEREIRA, A. R. Efeitos da vegetação na estabilidade de taludes e encostas. Boletim, Deflor Bioengenharia, ano 1, n. 20 p. 2006.

COUTO L. Técnicas de bioengenharia para revegetação de taludes no Brasil. Boletim Técnico: CBCN, nº 001, ISSN: 2177-305X. Viçosa - MG, 2010.

CUNHA, S. B. Geomorfologia fluvial. Volume I - O canal fluvial. São Paulo: Edgard Hlucher, ed. 2, p. 211-252, 1994.

DIAS, D. M.; SANTOS, E. C.; GOMES, D. P. P. Bioengenharia dos solos para estabilização de taludes aplicada nas indústrias nucleares do Brasil - INB. Itapetinga, Universidade Estadual do Sudoeste da Bahia, 2011.

DHITALA, Y. P.; TANG, Q. Soil bioengineering application for flood hazard minimization in the foothills of Siwaliksl. Ecological Engineering. v. 74, p. 458-462, 2015.

FATAHI, B.; KHABBAZ, H.; INDRARATNA, B. Melhoramento do terreno Bioengenharia Modelo absorção de Água da raiz. Ecologia e Engenharia, v. 36, p. 222-229, 2010.

GRAY, D. H.; SOTIR, R. Biotechnical and Soil Bioengineering Slope Stabilization: A Practical Guide for Erosion Control. John Wiley \& Sons, New York, 1996.

GUERRA, A. J. T.; CUNHA, S. B. (Org.). Geomorfologia: uma atualização de bases e conceitos. Rio de Janeiro: Bertrand Brasil, 2003.

HOLANDA, F. S. R.; SANTOS, L. G. C.; SANTOS, C. M. S.; CASADO, A. P. B.; PEDROTTI, A. Riparian fragments affected by bank erosion in the Lower São Francisco River, Northeastern Brazil. Revista Árvore, v. 29, n. 2, p. 148-152, 2005.

HOLANDA, F. S. R.; SANTOS, C. M.; CASADO, A. P. B.; BANDEIRA, A. A.; OLIVEIRA, V. S.; FONTES, L. C. S.; ROCHA, I. R.; ARAÚJO-FILHO, R. N.; GÓIS, S. S.; VIEIRA, T. R. S. Análise multitemporal e caracterização dos processos erosivos no Baixo São Francisco sergipano. Revista Brasileira de Geomorfologia, v. 8, n. 2, p.87- 96, 2007.

HOLANDA, S. R.; BANDEIRA, A. A.; ROCHA, I. P.; FILHO, R. N. A.; RIBEIRO, L. F.; ENNES, M. A. Controle da erosão em margens de cursos d'água: das soluções empíricas à técnica da bioengenharia de solos. RAEGA, n. 17, p. 93-101, 2009.

HOLANDA, F. S. R.; GOMES, L. G. N.; ROCHA, I. P.; SANTOS, T. T.; ARAÚJO FILHO, R. N.; VIEIRA,T. R. S.; MESQUITA, J. B. Crescimento inicial de espécies florestais na 


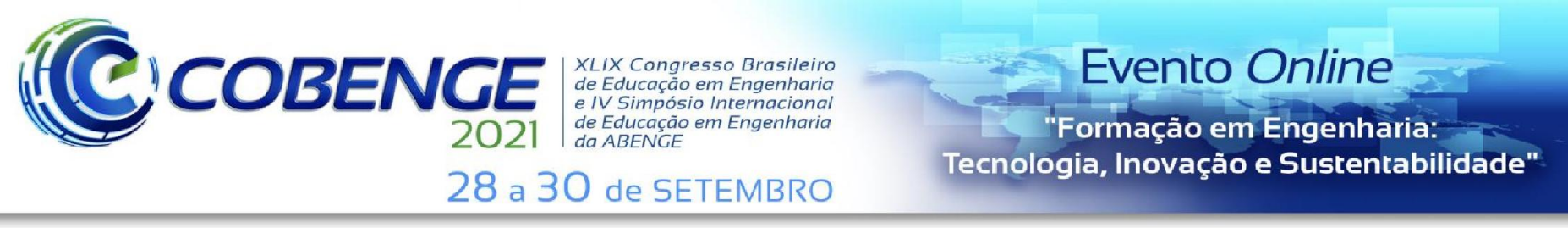

composição da mata ciliar em taludes submetidos à técnica da bioengenharia de solo. Ciência Florestal, v. 20, n. 1, p. 157-166, 2010.

KELLER, E. A. Hidrology and human use. In: Enviromental Geology, Charles E. Merril Publishing Company, p. 227-270, 1981.

LIU, Y.; RAUCH, H. P.; ZHANG, J.; YANG, X.; GAO, J. Development and soil reinforcement characteristics of five native species planted as cuttings in local area of Beijing. Ecological Engineering, v. 71, p. 190-196, 2014.

SAMAE - Sistema de Esgoto Sanitário da Cidade de Blumenau, Volume II: Estudo do Corpo Receptor - pg. 2-58. Santa Catarina, Brasil 06/02/02.

MARTINHO, P. R. M. Contribuição para o estudo de técnicas de engenharia biofísica: grade de vegetação e grade de vegetação Vesúvio. 2005. 95 p. Trabalho de Curso (Curso de Engenharia Biofísica). Universidade de Évora, 2005.

MELO, F. L.; SIMÃO, J. B. P.; CAIADO, M. A. C.; RANGEL, O. J. P. Vegetação como instrumento de proteção e recuperação de taludes. Revista Verde (Mossoró - RN BRASIL), v. 8, n. 5, p. 116 - 124, 2013.

PEREIRA, I. L. V. Estudos de revitalização de cursos d'água trecho experimental no rio das velhas. 2008. 122 f. Dissertação (Mestrado em Saneamento, Meio Ambiente e Recursos Hídricos) - Curso de Pós-graduação em Saneamento, Meio Ambiente e Recursos Hídricos, Universidade Federal de Minas Gerais, Belo Horizonte, 2008.

PETERSEN, S. L.; ROUNDY, B. A.; BRYANT, R. M. Revegetation methods for highelevation roadsides at Bryce Canyon National Park, Utah. Restoration Ecology, v. 12, n. 2, p. 248-257, 2004.

POMPÊO, C. A.; RIGOTTI, J. A.; FREITAS FILHO, M. D. Urban stream condition assessment. In: 12nd INTERNATIONAL CONFERENCE ON URBAN DRAINAGE, 2011, Porto Alegre/Brazil, p. 10-15.

SEVERO, D. A meteorologia do desastre. FRANK, B.; SEVEGNANI, L. Desastre de 2008 no Vale do Itajaí. Água, gente e política. Blumenau: Agência da Água do Vale do Itajaí. 2009.

SILVA, L. C. Manejo de rios degradados: uma revisão conceitual. Revista Brasileira de Geografia Física, n. 3, p.23-32, 2010.

SILVA, M. A. Aplicação de lógica nebulosa para previsão do risco de escorregamentos de taludes em solo residual. 150 f. Dissertação (Mestrado em Engenharia Civil) - Curso de Pós-graduação em Engenharia Civil, Universidade Estadual do Rio de janeiro, Rio de Janeiro, 2008.

SIMONS, L. I.; ASSOCIATES. Engineering Analysis of Fluvial Systems. Fort Collins: Simons. LI \& Associates, 1982. 


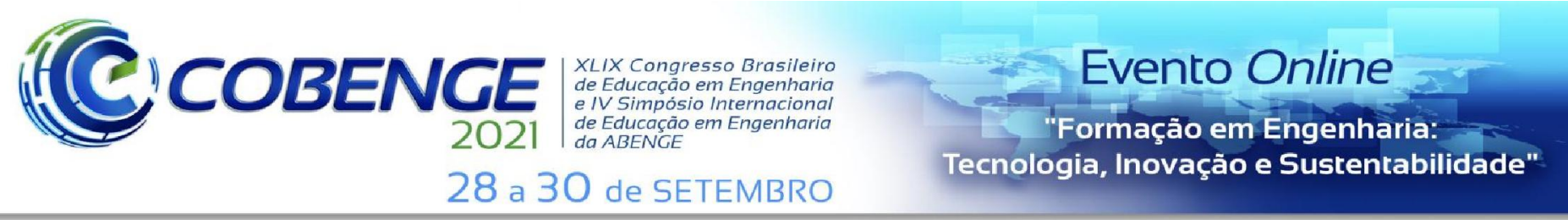

STOKES, A.; SOTIRB, R.; CHENC, W.; GHESTEMD, M. Soil bio-and ecoengineering in China: past experience and future priorities. Ecological Engineering, v. 36, p. 247-257, 2010.

SUTILI, F. J.; DURLO, M. A.; BRESSAN, D. A. Potencial biotécnico do sarandi-branco (Phyllanthus sellowianus) e vime (Salix viminalis) para revegetação de margens de curso de água, Ciência Florestal, v. 14, n. 1, 2004.

VIBRANS, A. C. A cobertura florestal da bacia do rio Itajaí - elementos para uma análise histórica. 240 f. Tese (Doutorado em Geografia) - Curso de Pós-Graduação em Geografia, Universidade Federal de Santa Catarina, Florianópolis, 2003.

XIA, J. Q; WU, B. S.; WANG, Y. P.; ZHAO, S. G. Analysis of soil composition and mechanical properties of riverbanks in a braided reach of the Lower Yellon River. Chinese Science Bulletin, v. 53, n. 15, p. 2400-2409, 2008.

\title{
THE INTEGRATED LEARNING LABORATORY AS A CURRICULAR COMPONENT IN ENGINEERING COURSES
}

\begin{abstract}
The natural dynamics of water courses have undergone constant actions of anthropogenic origin, which alter the stability of the slopes and slopes of the rivers. These impacts can be mitigated or avoided through appropriate civil engineering works or through bioengineering. Usually bioengineering techniques are used in conjunction with ecological principles, using vegetation and inert materials to stabilize and contain slopes. Given this context, the objective of this work was to analyze some of the works performed by conventional engineering, on the banks of the Itajaí-Açu river near the Adolfo Konder bridge in Blumenau-SC. And to evaluate how bioengineering can contribute to offering greater efficiency to the works, reducing costs, increasing the useful life and, consequently, causing less associated environmental impacts. At the same time, it was observed that the vegetation cover present on the margins has been significantly efficient in controlling erosion and soil slipping.
\end{abstract}

Keywords: Natural engineering. Bioengineering. Sustainability. 